\title{
Gastrinoma: A Small Tumor with Big Symptoms
}

\author{
Hira Irfan' ${ }^{1}$, Ahmed Imran Siddiqi ${ }^{1,2 *}$, Waqas Shafiq ${ }^{1}$ and Umal Azmat ${ }^{1}$ \\ ${ }^{1}$ Department of Endocrinology, Shaukat Khanum memorial cancer hospital and research center, Lahore, Pakistan \\ ${ }^{2}$ Department of Medicine Jersey General Hospital, Channel Islands UK
}

*Corresponding author: Ahmed Imran Siddiqi, Department of Endocrinology, Shaukat Khanum memorial cancer hospital and research center, Lahore, Pakistan; Department of Medicine Jersey General Hospital, Channel Islands UK

\section{ARTICLE INFO \\ Received: 兆 November 04, 2020 \\ Published: November 11, 2020}

Citation: Hira Irfan, Ahmed Imran Siddiqi, Waqas Shafiq, Umal Azmat. Gastrinoma: A Small Tumor with Big Symptoms. Biomed J Sci \& Tech Res 31(5)-2020. BJSTR. MS.ID.005159.

\section{ABSTRACT}

Gastrinoma is rare gastrin secreting tumor and can be challenging to diagnose in the absence of typical clinical features. Surgical resection remains the mainstay of treatment and can be curative, but the clinical presentation can compromise complete resection especially if the disease has already metastasized. We present here a 77-year-old lady with abdominal pain and secretory diarrhea. Gastrinoma was diagnosed in a stepwise approach of investigations and then surgically removed. Following surgery, the patient got prescribed octreotide for complete resolution of symptoms. Conservative treatment is only recommended for patients unsuitable for surgery, with widespread metastasis and on patients' own choice.

Abbreviations: NET: Neuroendocrine Tumors; ZES: Zollinger-Ellison Syndrome; MEN-1: Multiple Endocrine Neoplasia Type-1; SSTRs: Somatostatin Receptors; PTH: Parathyroid Hormone

\section{Introduction}

Gastrinomas are functional neuroendocrine tumors (NET) with excessive pathological secretion of a peptide hormone called Gastrin usually produced by gastric G-cells. These tumors are thought to originate from endodermal pluripotent cells. Gastrin is a physiological stimulus of the stomach parietal cells to produce gastric acid. Gastrinoma cells retain their functional ability to produce and secrete hormone but partially or completely lose their negative feedback inhibition function leading to unwanted and excessive volumes of gastric acid production, atypical stomach and intestinal ulceration and occasionally perforations often termed as Zollinger-Ellison syndrome (ZES). Gastrinoma is a rare NET with 0.1-15 cases per million individuals worldwide [1]. Gastrinoma may be sporadic or associated with multiple endocrine neoplasia type-1 (MEN-1). All patients with a Gastrinoma should be screened for MEN 1. Due to nonspecific symptoms Gastrinomas are usually diagnosed late. Typical symptoms include abdominal pain, secretory diarrhea, esophagitis, and hypercalcemia (4). Serum gastrin level is of great significance for initial screening, while diagnosis requires stepwise approach with help of imaging studies and is confirmed on pathological and immunohistochemical analysis. Surgical management remains the only curative treatment for a Gastrinoma (5). We report here a case of a 77-year-old lady diagnosed with a Gastrinoma. She underwent surgical resection with significant improvement in symptoms. After surgery, she was prescribed octreotides for further control of symptoms.

\section{Case Report}

A 77-year-old lady was referred to our Endocrinology clinic from Gastroenterology clinic for assessment of her stomach related symptoms. She had recently moved to England with a significant past medical history of stomach-related symptoms over the previous 10 years. She had been suffering from gradually worsening bouts of watery diarrhoea and vomiting for the previous ten years with a weight loss of 6 stones. The frequency and severity of her symptoms gradually got worse and was occasionally associated with abdominal pain, flushing, severe retching, and heartburns. Omeprazole and Ranitidine partially improved her symptoms, but the severity of residual symptoms kept getting worse over time. She had undergone a laparotomy for perforated anterior jejunal wall three years ago. During these ten years, she underwent extensive workup for her symptoms. Multiple upper GI endoscopies showed gastritis and duodenitis, biopsy confirmed oesophageal gastric 
metaplasia, chronic duodenitis and intestinal metaplasia of the stomach. Gastrin was mildly raised a few times; faecal elastase was very low suggesting exocrine pancreatic dysfunction. Urinary 5-hydroxyindoleacetic acid, tissue transglutaminase antibody, selenium, zinc, C1 elastase inhibitor and thyroid function test were all normal (Table 1). Small bowel meal and CT abdomen showed no abnormality except thickened lower oesophagus. At her clinic visit her BP was 152/86 mm/Hg with no lymphadenopathy and mild tenderness around her epigastrium.

Table 1: Initial investigations of patient.

\begin{tabular}{|c|c|}
\hline Investigations & Results \\
\hline TSH & $0.96 \mathrm{mIU} / \mathrm{L}(0.27-4.2 \mathrm{mIU} / \mathrm{L})$ \\
\hline FT4 & $17.4 \mathrm{pmoL} / \mathrm{l}(12-22 \mathrm{pmol} / \mathrm{L})$ \\
\hline Cortisol & $461 \mathrm{nmol} / \mathrm{L}$ \\
\hline Urinary 5 HIAA & $24 \mathrm{mg} / 2 \mathrm{~h}(2-7 \mathrm{mg} / 24 \mathrm{hours})$ \\
\hline C1 elastase inhibitor & Normal \\
\hline Urinary Normetanephrine & $532 \mathrm{mcg} /$ day $(122-624 \mathrm{mcg} /$ day $)$ \\
\hline Urinary Metanephrine & $437 \mathrm{mcg} /$ day $(232-824 \mathrm{mcg} /$ day $)$ \\
\hline Fecal Elastase & $252 \mathrm{~g} /$ faeces $(>500 / \mathrm{g}$ faeces $)$ \\
\hline Echocardiogram & No valvular abnormality \\
\hline Amylase & $77 \mathrm{IU} / \mathrm{L} \mathrm{(10-100} \mathrm{IU/l)}$ \\
\hline tTG antibody & Negative \\
\hline Gastrin & $655 \mathrm{pmol} / \mathrm{L}(0-40)$ \\
\hline
\end{tabular}

Table 2: Secretin Stimulation Test.

\begin{tabular}{|c|c|c|c|c|c|c|c|c|}
\hline Time (min) & $\mathbf{- 1 5}$ & $\mathbf{- 5}$ & $\mathbf{+ 2}$ & $\mathbf{+ 5}$ & $\mathbf{+ 1 0}$ & $\mathbf{+ 1 5}$ & $\mathbf{+ 2 0}$ & $\mathbf{+ 3 0}$ \\
\hline Gastrin (Pmol/l) & 6682 & 751 & 1656 & 1961 & 2281 & 1904 & 1653 & 1126 \\
\hline
\end{tabular}
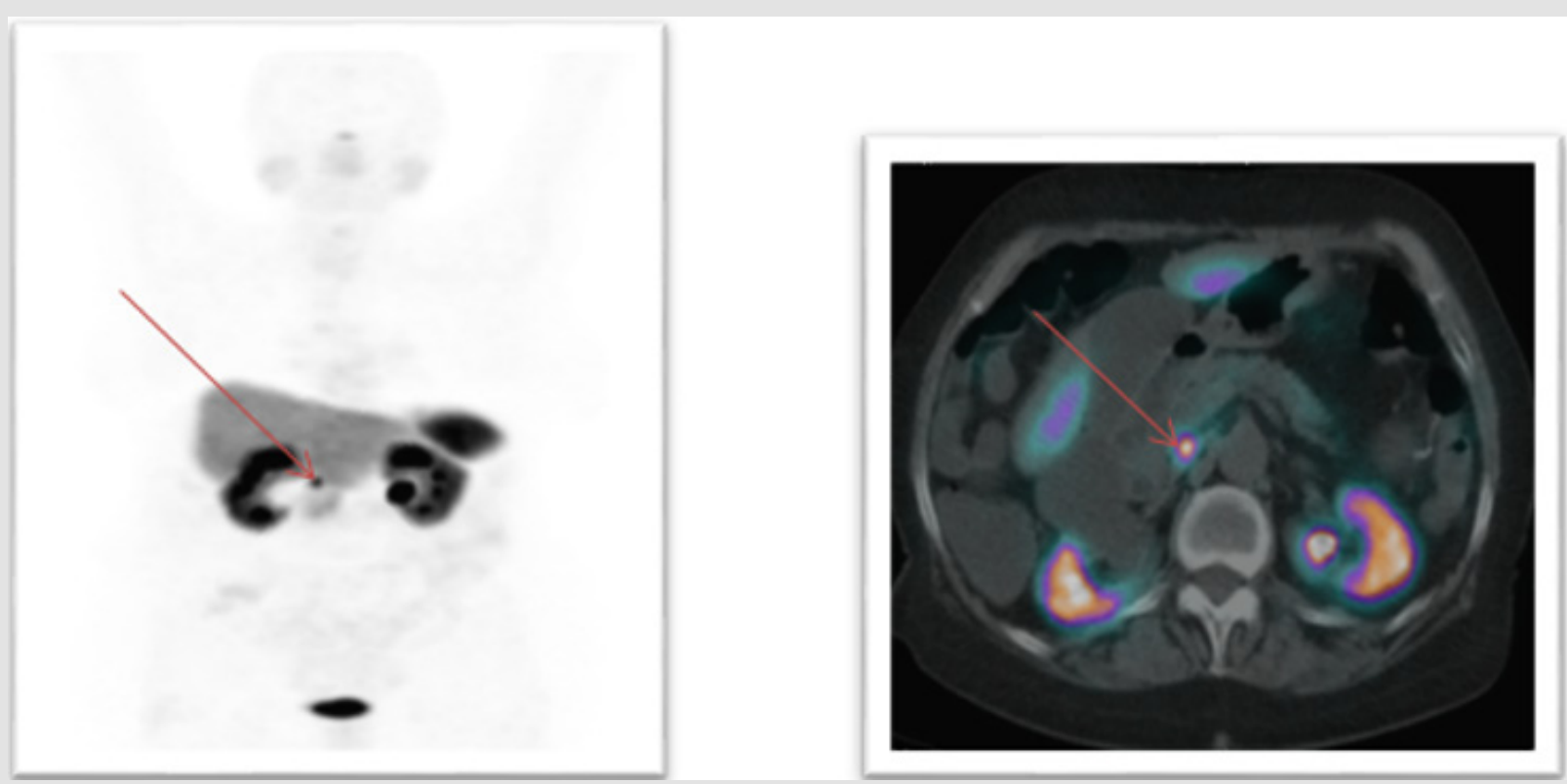

Figure 1: Pre surgical 68Ga-DOTATE PET scan; Red arrow marks location of lesion. 
Table 3: Laboratory tests before and after surgical resection.

\begin{tabular}{|c|c|c|c|}
\hline Investigations & Before surgery(Off PPI) & One month after surgery(on PPI) & Two months after surgery(on PPI) \\
\hline Gastrin $(0-40 \mathrm{pmol} / \mathrm{L})$ & 655 & 99 & 69 \\
\hline Somatostatin $(0-150 \mathrm{pmol} / \mathrm{L})$ & 81 & 60 & 73 \\
\hline VIP $(0-30 \mathrm{pmol} / \mathrm{L})$ & 16 & 5 & 5 \\
\hline Glucagon (0-50 pmol/L) & 5 & $<5$ & 175 \\
\hline Pancreatic polypeptide(0-300 pmol/L) & 87 & 55 & 50 \\
\hline CART (0-85 pmol/L) & 50 & 60 & 58 \\
\hline CgA (0-60 pmol/L) & 85 & 94 & 107 \\
\hline CgB $(0-150 \mathrm{pmol} / \mathrm{L})$ & 91 & & 58 \\
\hline
\end{tabular}

Note: CART, cocaine-and amphetamine-regulated transcript peptide; VIP, Vasoactive intestinal peptide; CgA, Chromogranin A; $\mathrm{CgB}$, Chromogranin B.

\section{Discussion}

Rare gastrin secreting neuroendocrine tumor, Gastrinoma is classically characterized by clinical disorder Zollinger Ellison syndrome (ZES). It was first reported by Zollinger and Ellison in 1955 [1-5] ZES leads to the development of peptic ulcer disease due to gastric acid hypersecretion [6]. Similar to that seen in our current case, diarrhea has been shown to be one of the most common symptoms, with its presence documented in $>70 \%$ of patients. Up to ninety percent of Gastrinomas are thought to arise from Gatsrinoma triangle. Gastrinoma triangle or Passaro's triangle is an imaginary triangle comprising of pancreas medially, second and third part of duodenum inferiorly and the confluence of cystic and common bile duct superiorly. It is an important anatomical landmark for tumor localization. Gastrinomas are mostly located in the duodenum and few are located in the pancreas $[3,7,8]$. Occasionally, Gastrinomas have also been described in other areas, including lymph nodes, biliary tree, ovaries, kidneys, heart, gallbladder, omentum and liver. In advanced cases, liver is the most common site for metastasis. The duodenal and pancreatic Gastrinomas behave similarly clinically [6]. Most Gastrinomas are sporadic in origin but in $20-30 \%$ of cases these may be associated with Multiple Endocrine Neoplasia-type 1 (MEN1) [4].

The pathogenesis of sporadic Gastrinomas remains unclear [5]. Majority of patients with sporadic Gastrinomas are men between the ages of 30 and 50 years. Our patient presented at a relatively older age. A Review of literature revealed that was relatively one of the few cases of Gatsrinomas which were diagnosed in old age. MEN 1 is a genetic autosomal dominant disease, mutations occur in the gene MEN1, leading to the formation of multiple neoplasia out of which pancreatic endocrine tumors, pituitary adenomas, and hyperplasia of the parathyroid are the most prevalent. Gastrinomas are more frequently associated with neuroendocrine tumors with MEN 1 in contrasts to Insulinomas and Glucagonomas $[3,5]$. The initial screening test is fasting gastrin level. It is important to distinguish ZES from all other physiological causes of hypergastrinemia by assessment of gastric $\mathrm{pH}$ and/or acid output
$[7,9,10]$. To distinguish ZES from other causes of inappropriate hypergastrinemia (H. pylori infection, etc.), additional studies such as determination of a basal acid output (BAO), a secretin provocative test or possible assessment for presence of a neuroendocrine tumor (NET) using somatostatin receptor scintigraphy (SRI) with either 68Ga-DOTATATE PET/CT or 111In-DTPA-octreotide with SPECT/ CT(SRS) imaging are recommended. The somatostatin receptors (SSTRs) are overexpressed on NETs cells. The 68Ga-DOTA-peptides bind to these receptors, efficiently making it possible to localize even smaller lesions. In our patient fasting serum gastrin level was raised so we carried out secretin stimulation test to rule out other causes of hypergastrinemia.

After stimulation with secretin, gastrin level increased from 682 $\mathrm{pmol} / \mathrm{L}$ to $1126 \mathrm{pmol} / \mathrm{L}$ which strengthened our clinical suspicion of a Gastrinoma. Later on, we carried out 68Ga-DOTATATE PET/CT which showed a DO TA avidlesion in the head of pancreas. There were many controversies in past regarding effective methods for diagnosis of ZES. Assessment of gastric $\mathrm{pH}$ and basal acid output requires technical expertise and provocative tests (secretin stimulation test) depends on many factors including prior or current use of PPI. The use of PPI may give false negative results. Moreover, the role of nonbiochemical testing for ZES is of increasing importance because of recent advances in neuroendocrine tumor specific imaging studies with SRI using either 68Ga-DOTATATE PET/CT or 111In-DTPAoctreotide with SPECT/CT imaging. These imaging modalities are now becoming increasingly available and numerous studies show they have excellent sensitivity and specificity for NETs $[11,12]$. Somatostatin receptor studies have a sensitivity of $40-60 \%$ for duodenal Gastrinomas and 60-100\% for pancreatic Gastrinomas [11-13]. It has a reported false positive rate of $0-12 \%$ but is higher in MEN1/ZES patients because of the multiple endocrine tumors these patients develop. With improvements in imaging, the role of biopsy or cytology in diagnosing ZES, particularly in patients with advanced disease or typical presenting symptoms, is less clear.

All ZES patients must be screened for MEN1 syndrome initially and re-evaluated with time [4,14]. The presence of MEN1/ZES 
needs family counseling as well as the need to search for other endocrinopathies. MEN syndrome is associated with many functional and nonfunctional NETs and the presence of these tumors has a major impact on the clinical management approach to the Gastrinoma itself. Our patient had a normal parathyroid hormone level (PTH) and blood calcium levels and was subsequently diagnosed with sporadic Gastrinoma. In addition, chromogranin A has been used as a tumor marker for NETs, with a sensitivity of $59 \%$ and a specificity of $100 \%$ [15]. In our case chromogranin A was raised before resection that dropped to normal range after resection of the lesion. Treatment of a Gastrinoma aims towards control of symptoms by controlling hormone excess and its surgical resection. Without effective medical treatment, gastric acid hypersecretion can cause severe complications including bleeding, penetrating stomach and intestinal ulcers and fatal outcomes [16,17]. Initially, only total gastrectomy adequately controlled the profound acid hypersecretion. However, with the availability of proton pump inhibitors [18-22], medical control of acid hypersecretion, both acutely and long-term, is possible in the majority of patients. Surgical resection of the tumor is the only curative treatment of a Gastrinoma.

All patients with sporadic ZES with respectable disease and having no medical contraindication limiting surgery should undergo surgical removal of tumor. Lymph node dissection should be performed even if no primary tumor is identified due to the possibility that the primary tumor may have occurred in the (peripancreatic) lymph nodes. Results from studies [17,23,24] have demonstrated that surgical resection extends overall- and diseaserelated survival and also decreases the subsequent development of liver metastases, which are the main determinant of longterm survival in these patients [25-28]. Although the majority of Gastrinomas grow slowly 50-60\% are malignant and have already metastasized at diagnosis [29]. A metastatic malignant Gastrinoma has 5-year survival rate of 20-38\% [29]. If tumor has metastasized then control of symptoms is only achieved with medical therapies. In our case, there was no distant metastasis and tumor was localized to head of pancreas. It was surgically resected and postoperative imaging (Figure 2) confirmed the complete removal of lesion. Gastric hypersecretion may be controlled effectively using PPIs and H2-blockers. However, somatostatins, such as octreotide, have also been used to inhibit the hypersecretion of gastric acid [23]. A routine use has not been established and randomized trials are required. Chemotherapy may be administered for patients with widespread metastasis and those unfit for surgery. The first-line treatment is combined therapy with streptozotocin and 5-fluorouracil or doxorubicin [26].

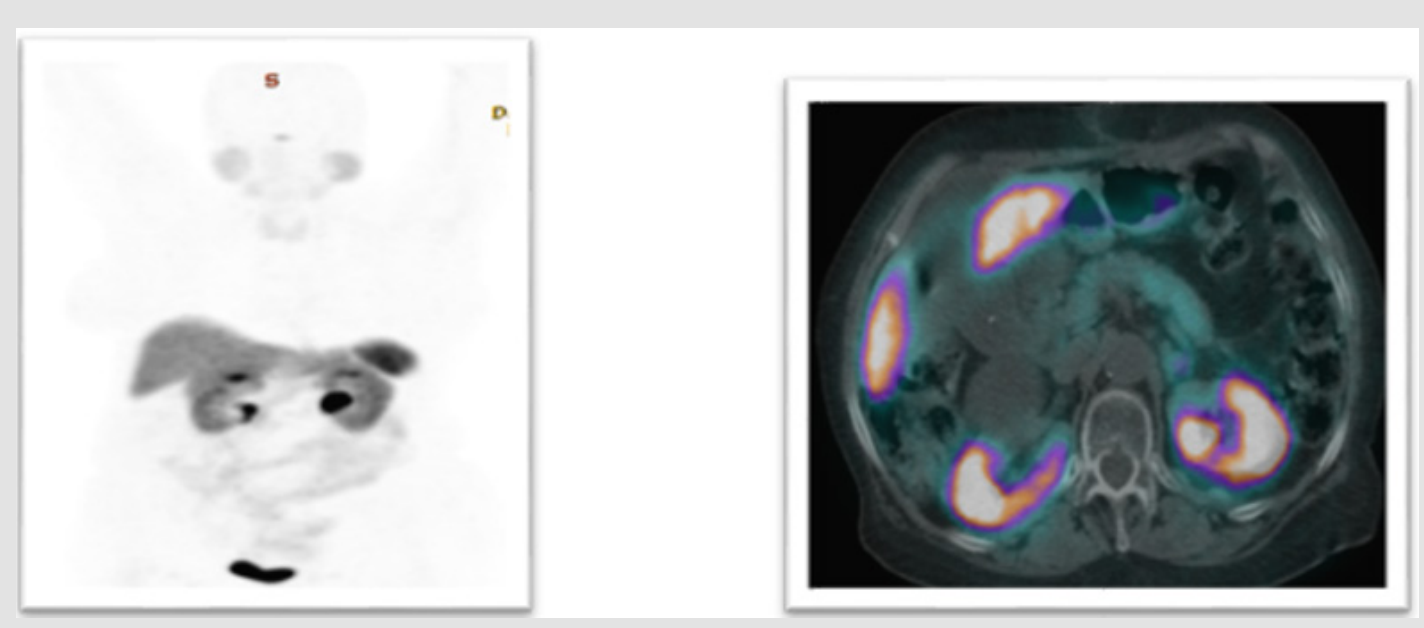

Figure 2: Post-surgical 68Ga-DOTATATE PET scan; complete resection of lesion.

In patients with well-differentiated metastatic Gastrinomas chemotherapy results in objective response rates of $20-40 \%$, however complete response rates are uncommon, and the responses are generally not long-term (mean 5-20 months). Poorly differentiated Gastrinomas characteristically show rapid growth with a poor prognosis.

\section{Learning points}

1. Our patient presented with a sporadic Gastrinoma at a relatively older age and we suggest clinicians should always suspect atypical presentations of any disease.
2. Clinicians should always think out of the box to diagnosed uncommon conditions if standard therapies fail to achieve the expected outcomes.

\section{References}

1. Hung PD, Schubert ML, Mihas AA (2003) Zollinger-Ellison syndrome. Current treatment options in gastroenterology 6(2): 163-170.

2. Zollinger RM, Ellison EH (1955) Primary peptic ulcerations of the jejunum associated with islet cell tumors of the pancreas. Annals of surgery 142(4): 709-723.

3. Ito T, Igarashi H, Jensen RT (2012) Pancreatic neuroendocrine tumors: Clinical features, diagnosis, and medical treatment: Advances. Best practice \& research Clinical gastroenterology 26(6): 737-753. 
4. Gibril F, Schumann M, Pace A, Jensen RT (2004) Multiple endocrine neoplasia type 1 and Zollinger-Ellison syndrome: A prospective study of 107 cases and comparison with 1009 cases from the literature. Medicine 83(1): 43-83.

5. Metz DC, Jensen RT (2008) Gastrointestinal neuroendocrine tumors: Pancreatic endocrine tumors. Gastroenterology 135(5): 1469-1492.

6. Andersen DK (1989) Current diagnosis and management of ZollingerEllison syndrome. Annals of surgery 210(6): 685-703.

7. Roy PK, Venzon DJ, Shojamanesh H, Abou Saif A, Peghini P, et al. (2000) Zollinger-Ellison syndrome: Clinical presentation in 261 patients. Medicine 79(6): 379-411.

8. Norton JA, Fraker DL, Alexander HR, Venzon DJ, Doppman JL, et al (1999) Surgery to cure the Zollinger-Ellison syndrome. New England Journal of Medicine 341(9): 635-644.

9. Jensen RT, Niederle B, Mitry E, Ramage JK, Steinmüller T, et al. (2006) Gastrinoma (duodenal and pancreatic). Neuroendocrinology 84(3): 173-182.

10. Osefo N, Ito T, Jensen RT (2009) Gastric acid hypersecretory states: Recent insights and advances. Current gastroenterology reports 11(6): 433-441.

11. Gibril F, Reynolds JC, Chen CC, Yu F (1999) Specificity of somatostatin receptor scintigraphy: A prospective study and effects of false-positive localizations on management in patients with gastrinomas. The Journal of Nuclear Medicine 40(4): 539-553.

12. Fendler WP, Barrio M, Spick C, Allen Auerbach M, Ambrosini V, et al. (2017) 68Ga-DOTATATE PET/CT interobserver agreement for neuroendocrine tumor assessment: Results of a prospective study on 50 patients. Journal of Nuclear Medicine 58(2): 307-311.

13. Atema JJ, Amri R, Busch OR, Rauws EA, Gouma DJ, et al. (2012) Surgical treatment of gastrinomas: A single-centre experience. HPB 14(12): 833838.

14. Benya RV, Metz DC, Venzon DJ, Fishbeyn VA, Strader DB, et al. (1994) Zollinger-Ellison syndrome can be the initial endocrine manifestation in patients with multiple endocrine neoplasia-type I. The American journal of medicine 97(5): 436-444.

15. Nehar D, Lombard Bohas C, Olivieri S, Claustrat B, Chayvialle JA, et al. (2004) Interest of Chromogranin A for diagnosis and follow-up of endocrine tumours. Clinical endocrinology 60(5): 644-652.

16. Go VL (1993) The pancreas: Biology, pathobiology, and disease.

17. Mignon M, Cadiot G (1999) Natural history of gastrinoma: Lessons from the past. Italian journal of gastroenterology and hepatology 31: S98-103.

\section{ISSN: 2574-1241}

DOI: $10.26717 /$ BJSTR.2020.31.005159

Ahmed Imran Siddiqi. Biomed J Sci \& Tech Res

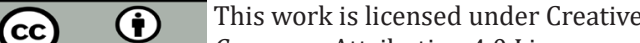

Commons Attribution 4.0 License

Submission Link: https://biomedres.us/submit-manuscript.php
18. Ito T, Igarashi H, Uehara H, Jensen RT (2013) Pharmacotherapy of Zollinger-Ellison syndrome. Expert opinion on pharmacotherapy 14(3): 307-321.

19. Nieto JM, Pisegna JR (2006) The role of proton pump inhibitors in the treatment of Zollinger-Ellison syndrome. Expert opinion on pharmacotherapy 7(2): 169-175.

20. Phan J, Benhammou JN, Pisegna JR (2015) Gastric hypersecretory states: Investigation and management. Current treatment options in gastroenterology 13(4): 386-397.

21. Metz DC, Sostek MB, Ruszniewski P, Forsmark CE, Monyak J, et al. (2007) Effects of esomeprazole on acid output in patients with Zollinger-Ellison syndrome or idiopathic gastric acid hypersecretion. American Journal of Gastroenterology 102(12): 2648-2654.

22. Norton JA, Fraker DL, Alexander HR, Jensen RT (2012) Value of Surgery in Patients with Negative Imaging and Sporadic Zollinger-Ellison Syndrome (ZES). Annals of surgery 256(3): 509-517.

23. Norton JA, Fraker DL, Alexander HR, Jensen RT (2012) Value of Surgery in Patients with Negative Imaging and Sporadic Zollinger-Ellison Syndrome (ZES). Annals of surgery 256(3): 509-517.

24. Norton JA, Fraker DL, Alexander HR, Gibril F, Liewehr DJ, et al. (2006) Surgery increases survival in patients with gastrinoma. Annals of surgery $244(3):$ 410-419.

25. Singh MH, Fraker DL, Metz DC (2012) Importance of surveillance for multiple endocrine neoplasia-1 and surgery in patients with sporadic Zollinger-Ellison syndrome. Clinical Gastroenterology and Hepatology 10(11): 1262-1269.

26. Fraker DL, Norton JA, Alexander HR, Venzon DJ, Jensen RT (1994) Surgery in Zollinger-Ellison syndrome alters the natural history of gastrinoma. Annals of surgery 220(3): 320-330.

27. Yu F, Venzon DJ, Serrano J, Goebel SU, Doppman JL, et al. (1999) Prospective study of the clinical course, prognostic factors, causes of death, and survival in patients with long-standing Zollinger-Ellison syndrome. Journal of Clinical Oncology 17(2): 615-630.

28. Fendrich V, Langer P, Waldmann J, Bartsch DK, Rothmund M (2007) Management of sporadic and multiple endocrine neoplasia type 1 gastrinomas. British journal of surgery 94(11): 1331-1341.

29. De Herder WW, Lamberts SW (2004) Gut endocrine tumours. Best Practice \& Research Clinical Endocrinology \& Metabolism 18(4): 477 495.

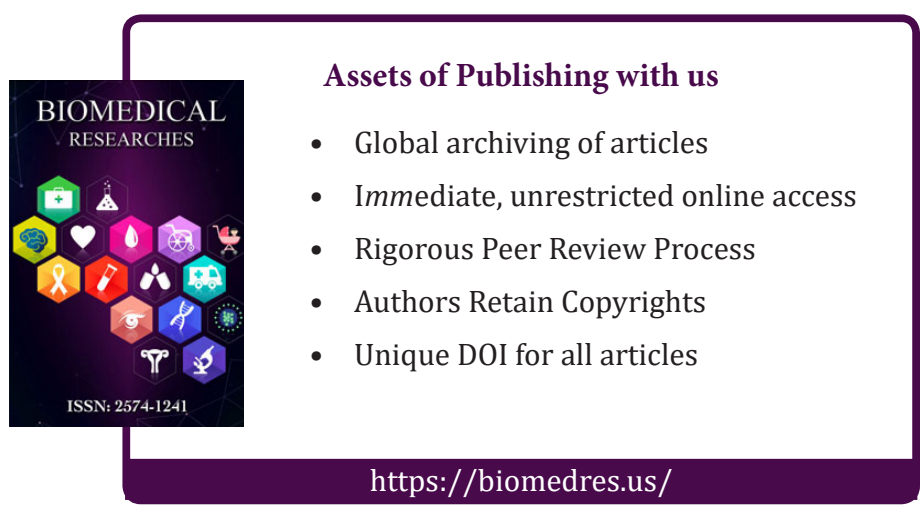

Copyright@ Ahmed Imran Siddiqi | Biomed J Sci \& Tech Res | BJSTR. MS.ID.005159. 